\title{
Stabilizing the Euro area and overcoming the confidence crisis
}

\author{
Paul J. J. Welfens
}

Published online: 25 January 2012

(C) Springer-Verlag 2012

After a successful starting decade, the Euro zone is heading towards very serious problems and this is partly because of inadequate national policies of some member countries and partly due to a doubtful crisis management. As regards the former, the Greek deficit of 2009 with a deficit-GDP ratio of $15 \%$ is as crucial as the Irish deficit shock of $32 \%$ in 2011 where $2 / 3$ was a one-off effect of the government's recapitalization of banks which for years had acted under "light" (totally ineffective) supervision. Italy with its high debt-GDP ratio is also a problem in the context of nervous financial markets, higher risk premiums and a general increase in debt-GDP ratios in both the US and Europe in the period of 2007-2011.

The crisis management of the European Council has not been effective, including the problem of haircuts for Greece in 2011, which were imposed against warning from the ECB - the risk that confidence in bonds markets would be undermined was not taken seriously. In late November 2011, the prices of credit default swaps have been rising for almost all Euro area countries and liquidity in the interbank markets had dried out in almost all Euro countries except for Germany. The Belgish-FrenchLuxumbourgian Dexia bank was the first big EU bank from those that had been rescued in the Transatlantic Banking Crisis that needed new rescue funding in late 2011. From an analytical perspective macroeconomic analysis should be refined and revised in several ways (Welfens 2011).

This analysis is based on my contribution to the Global Jean Monnet Conference, Brussels/Charlemagne building, Nov. 25-26, 2011. I have benefitted from discussions with Robert Mundell, Columbia University; I am also grateful for discussions with Michael Klein, Tufts University, Boston. I take full responsibility for the analysis presented.

\section{P. J. J. Welfens $(\bowtie)$}

European Institute for International Economic Relations, University of Wuppertal,

Rainer-Gruenter-Strasse 21,

42119 Wuppertal, Germany

e-mail: Welfens@wiwi.uni-wuppertal.de

URL: www.eiiw.eu

URL: www.econ-international.net 
The Greek haircut was taken by markets as a model for other high debt countries, therefore, the Greek debt reduction of $€ 37$ bill. expected from the $21 \%$ haircut of July 21 went along with some expected $€ 360$ bill. of wealth losses for Italian bond holders if a $20 \%$ haircut were to be applied (the haircut was increased to $50 \%$ in October 2011); this is a remarkable and strange benefit-cost ratio and this has destroyed much of the confidence in Euro capital markets. Moody's wrote on May 2011 (Moody's 2011) in a publication: "On contagion to other sovereigns: Other distressed euro area sovereigns would face the prospect of a long-term denial of access to capital markets and, at the same time, lower expectations of support over the medium term from the rest of the euro area. (...) A confirmation that the euro area was willing to let one of its members default would inevitably cause investors to reassess the limits of the euro area support. That, together with the assumption that other weak euro area sovereigns might be more likely to choose to take similar steps to Greece-particularly if a Greek restructuring were perceived as 'orderly' — could result in Ireland and Portugal, and perhaps stronger countries such as Spain and even Italy and Belgium, finding market access considerably more expensive."

The temporary Euro rescue fund EFSF is running out of steam even before plans for leveraging the fund could be implemented: As the EFSF could issue bonds for $4.4 \%$ in late November 2011, which was more than $2 \%$ above the interest rate for German Bunds, the capital markets are signaling that they do not have a lot of confidence in a stable AAA rating of the country group with top rating behind the EFSF: Finland, Luxembourg, the Netherlands, Germany, Austria and France-hence the EFSF is no vehicle for mobilizing big rescue sums, it has become an indicator of the growing lack of confidence in "Euro bonds markets".

The AAA rating of France had been called into question by Moody's in November 2011. Any multilateral rescue fund set up in the Euro area suffers from a double problem: The countries that have rallied behind the fund might suffer a considerable downgrading and there is no credible lender of last resort for an individual country or a country group in the Euro area. The only credible institution left in the EU-also bringing indefinite liquidity and strong solvency-is the European Central Bank; however it has not been very active so far.

The ECB feels at odds when intervening in the bonds market as this could be interpreted in a way that undermines its commitment to low inflation and its stability reputation, respectively. So far, there is a virtual Euro bonds market since governments of Euro member countries are placing national bonds into the market on an individual basis. The switch to a truly integrated Euro bonds market with a uniform interest rate across countries could basically be achieved by establishing a Euro Political Union; but this will take time. The German government is trying with partner countries to change the key rules in the Euro Area, but again this will take time and one can only warn Berlin to bet on a political speculation which wants to generate from hyper-nervous financial markets the pressure that partner countries should follow desired new budget rules - the financial markets in late 2011 are extremely fragile and once strong momentum builds up in these markets to bet on a collapse of the Euro Area policy makers will be totally unable to control the dynamics of the Tsunami emerging. The fact that the British supervisory authority FSA has called on British banks in November to consider extreme developments as an element 
of risk management is a quasi-official warning from the UK that time for political games in the Euro Area is running out.

The stabilization bridge necessary in the interim is to start an ECB program that would place supranational ECB Euro bonds on the market. There could be a program where the ECB acts as a true lender of last resort by buying national Euro bonds of all Euro countries in exchange for ECB Euro bonds. Each government could exchange debt of up to $50 \%$ of its GDP. Countries with a debt-GDP ratio below $60 \%$ could exchange even up to $60 \%$ of its GDP into ECB bonds which would have even higher liquidity than traditional Bunds of Germany since the ECB is a credible lender of last resort behind the new supranational "quasi Euro-federal" bonds. The abnormal situation that the average Euro interest rate exceeds that of the US or the UK-both having a lender of last resort, while so far the Euro Area has no such lender-would thus end and the Euro Area would be stabilized. At the same time, it is necessary that the European Council stops its dangerous interventionism which was full of good intentions but has led to poor results; the Council is not effectively controlled by any parliament and the lack of timely discussion might partly explain the poor results.

Apparently no international treaty has to be changed if the ECB wants to place Euro bonds on the market which might involve the EFSF in order to get explicit legitimacy. This activity would come under the heading of the task that the ECB should contribute to the stability of the financial system. It should be noted that both the central bank in China and in Korea have issued their own bonds. Structural reforms in many Euro countries remain, of course, urgently necessary.

A potential problem of ECB Euro bonds is that interest payments have to be offered and it is not fully clear whether incoming interest payments on the stock of debt in ECB's books will be sufficient to cover the necessary interest payment. If the ECB buys roughly $1 / 2$ of the existing Euro bonds, which it would exchange for supranational ECB bonds, the interest to be paid on about $€ 4000$ bill. supranational debt would be about $€ 120$ bill. (the expected interest rate on ECB Euro bonds is 2$3 \%$ while the interest rate on Euro bonds guaranteed and issued by Euro governments jointly would have to carry an interest rate of about $6 \%$ if one considers the benchmark of the $4.4 \%$ the EFCF paid in November 2011; governments in the Euro Area have lost much credibility in capital markets in 2011 while the ECB has remained fully credible). This potential problem, however, could be solved in two ways: The ECB could get a guarantee from the EFSF, namely insurance against the case that insufficient interest payments are accruing-read: one of the Euro countries goes into partial default; and it could get reassurance from private reinsurance companies. The ultimate option is that the ECB acts as a lender of last resort that can print as much high powered money as needed to pay off the interest and principal on the ECB $€$ bonds. Banks should get privileged exchange of Euro bonds so that new supranational risk-free ECB $€$ bonds would be their preferred safe assets - with zero bank equity weight under prudential supervision rules. The ECB should start the new program quickly. The proposed asset swap is neither a bail-out nor is the ability of the ECB to control the money supply adequately undermined, rather the new truly common supranational interest rates will reinforce the ECB's ability to conduct monetary policy and use transmission mechanisms in a traditional and effective way. 
It would be wise to carefully implement a program with ECB $€$ bonds placement, while not distorting the yield curve in the Euro area. At the same time, adequate constitutional debt brakes should be adopted in all Euro countries. The Euro zone's unsolved stabilization problem is undermining recovery in the UK, the US and part of Eastern Europe. There is a high likelihood that unsolved government debt crises in Euro countries will lead to a new banking crisis and a massive recession. Governments in Europe and North America - some of which already seem to be 'overborrowed'would not have much room to maneuver in fiscal policy and bank recapitalization. Hence the ECB should issue supranational Euro bonds on the basis of a broader agreement with national governments of the Euro Area, respectively.

\section{Implications of multiple equilibriums for adequate stabilization strategy}

The crisis management of Berlin and Paris is rather confusing and the European Council — not controlled by a parliament or critical discussions - has made many doubtful and inconsistent decisions in 2011. The EU Council of December 8 made doubtful results because the move towards a fiscal union could not be implemented within the revision of the Lisbon Treaty - the UK did not want to participate in this whole project and demanded special derogations in the field of financial market regulation. As the EU partner countries did not want to yield to British pressure, the Euro 17 countries plus nine other countries decided that they would embark upon a separate new treaty on the principles of a fiscal union. However, it is unclear which rules will be relevant for deficit control in the future as there should both be the Lisbon Treaty-with Article 126 and its focus on deficits and debts - and a new treaty on principles of a fiscal union. Another problem concerns the role of the IMF, whose capital basis EU countries want to reinforce while the US is apparently quite reluctant to give additional funds to the IMF.

As rating agencies, S\&P and Moody's, have put Euro countries on watch in December 2011, the problem of critically high interest rates will play a critical role within the next few months. The high interest rates for Italy and Spain are largely due to the strange double Greek haircut decision for which Germany's government has pushed for unclear reasons. While the first haircut of July 21 might be defendable to some extent, the decision to adopt a 50\% haircut in October 2011 is extremely doubtful as it suggests not only that the value of government bonds of EU countries could fall very strongly, it also makes clear that the decisions of the European Council cannot be trusted (in the form of the Euro group). Instead of making a clear and wellfounded decision - in this case referring to private sector involvement and the Greek haircut - and sticking to it, the heads of the Euro member countries have revised decisions within a few months and the impression was created that the Council's agenda and decisions were two steps behind instead of providing leadership with at least one step ahead. The Merkel government has emphasized that a strategy of making small steps would be the right way to make progress with respect to solutions of key problems. In Berlin, politicians initially had big plans for a very big rescue umbrella but government had weak analytical foundations right at the beginning in 2010 and would rather follow the advice of rating agencies that would pursue a distinct strategy based on its own thorough analysis. 
At the end of 2011 it is clear that the rescue umbrella EFSF is too small to accommodate the potential needs of countries such as Italy and Spain. The latter has a debt-GDP ratio which is below that of Germany but the interest rate to be paid for long-term debt is much higher than that of German bonds. Interest rates of $6 \%$ forced Ireland and Portugal to go under the EFSF rescue umbrella; the 7\% that had to be paid by Italy in late autumn is not sustainable for Italy in the long run and as soon as capital markets anticipate that Italy will be unable to get lower interest rates in the medium- and long term, the country will face default. This is one potential equilibrium towards which the German-Franco crisis management and Greek contagion effects are leading and in the end this could destroy the Euro zone. A second equilibrium solution is the setting of a low interest rate that can be brought about by ECB intervention. The ECB could guarantee all countries with a minimum primary surplus that it would buy at a maximum 5\% interest rate any amount of bonds offered by the respective countries. This would stabilize Spain and Italy and the banking systems in the Euro Area; this strategy is adequate since Spain and Italy are not insolvent unless there is an overshooting of interest rates at $7 \%$ (or above) and a vicious circle of downgrading certain countries takes place, higher CDS prices and rising interest rates are accepted by indifferent policy makers. To control a potentially strong liquidity expansion, the ECB should create its own ECB euro bonds which would require some backup by Euro countries.

The apparent approach of the German government in 2011 was to push Italy and Spain towards desirable reforms through the pressure of market forces and very high interest rates. However, this strategy is very risky in a very nervous market environment. Germany's government and its Euro partners might soon face a Tsunami in financial markets, whose seed has been planted by certain governments in the monetary union. At the bottom line, it is clear that there are very few viable euro stabilization options and certainly short-term adjustment and crisis management should go along with a clear view on required long-term structural reforms in many EU countries.

The Euro Area faces a serious problem following the crisis in Greece where governments have not been encouraged by the double haircut to adopt comprehensive privatization and structural change. Athens stands for policy failure and distinct political risk within the Euro Area, due to the weak supervision of the EU in the past. Hence in order to resume growth in Greece, the EU- not only the Euro Areashould launch a Marshall Plan with conditions attached with respect to broad privatization, the introduction of a flat rate tax and other reforms for Greece.

As regards the UK and the US the enormous Quantitative Easing (QE) programs which made the Bank of England and the Fed acquire government bonds of about $20 \%$ of GDP and $15 \%$ of GDP in 2008-2011, respectively, have brought about three main short term effects, which can be analyzed with a portfolio model and a modified Mundell Fleming model with QE (Welfens 2012; for the first time, a modified Branson model is also combined with the Solow model and debt dynamics): a fall in the interest rate, a depreciation of the currency and a parallel expansionary fiscal policy. Without QE in the UK, the US and Japan the euro would have depreciated considerably in 2010/2011. Moreover, the British economy looks rather weak, as the combination of QE and a 9\% deficit-GDP ratio in 2011 could not bring about a strong recovery. 
While the crisis management of the EU/Euro council has been miserable in 2011, the Euro Area economy looks fairly robust compared to the UK and the US. The deficit-GDP ratio is lower than in the UK and the US in 2011 and the overall debtGDP ratio is lower than in the US and close to that of the UK-a point which has been emphasized along with considerations referring to the required reforms in the 2011 Brussels Manifesto of Jean Monnet Chairs, which was jointly initiated by Alberto Alemanno (Paris), Sylvester Eijffinger (Tilburg), Cillian Ryan (Birmingham) and myself (Brussels Manifesto, 2011).

Finally, adopting QE in the Euro Area should be considered carefully. While starting QE is not difficult, particularly in the form of an expansionary open market operation in which the central bank acquires long run government bonds, the issue of finding an exit option, which does not undermine economic stability, is rather complex. Once the situation in Greece has been stabilized and an intelligent form of creating Euro ECB bonds has been defined - possibly along with a conditional interest rate cap for euro countries achieving a certain primary deficit-GDP surplusthe Euro Area crisis should be overcome provided that national debt brake rules and a fiscal union plus necessary structural reforms are adopted. The long run solution is a Euro Political Union.

\section{References}

Brussels Manifesto of Jean Monnet Chairs (2011), Stabilizing the Euro Area and the EU, www.eiiw.eu (showing also the list of 97 Jean Monnet Chair holders who have signed the manifesto)

Moody's (2011) Assessing the effect of a potential Greek default, Memo, May 24, 2011

Welfens PJJ (2011) Innovations in macroeconomics, 3rd edn. Springer, Heidelberg

Welfens PJJ (2012) Quantitative Easing in a Schumpeterian Open Economy Growth Model, Working Paper 210, European Institute for International Economic Relations at the University of Wuppertal (www. eiiw.eu), January 2012, forthcoming 